\title{
Controle e valorização da liberdade de expressão no mundo do trabalho
}

\section{Control and enhancement of freedom of expression in the world of work ${ }^{1}$}

Fernando Felício Pachi Filho ${ }^{2}$

Valéria Feitosa de Moura ${ }^{3}$

Resumo: Neste artigo, apresentamos resultados de pesquisa realizada com trabalhadores de sete organizações, com objetivo de identificar como a liberdade de expressão é significada e vivenciada em ambientes de trabalho. Nesse sentido, utilizaremos como aportes teóricos o binômio comunicação e trabalho, e os estudos ergológicos. Os dados foram coletados por meio de questionários e mostram que as organizações conferem parâmetros para a liberdade de expressão. O direito à liberdade de expressão é reconhecido e valorizado, porém os limites se inserem em contextos nos quais os trabalhadores têm pouca margem para estabelecê-los. As preocupações com danos à empresa e a manutenção da boa convivência são as principais razões apontadas para a necessidade de limites. Possíveis riscos à segurança e danos à imagem tanto de trabalhadores quanto das organizações se difundem como consequências de uma expressão livre.

Palavras-chave: Liberdade de expressão; comunicação e trabalho; direitos humanos.

\footnotetext{
Abstract: In this article, we present results of research carried out with workers from seven organizations, aiming to identify how freedom of expression is signified

1 Uma versão deste texto foi apresentada no Comunicom 2018 no GT Comunicação, Cultura empreendedora e trabalho: consumo, narrativas e discursos.

2 Universidade Paulista (UNIP) e Faculdade de Tecnologia Termomecanica (FTT). São Paulo, SP, Brasil.

https://orcid.org/0000-0002-1667-4937 E-mail: fernando.filho@usp.br

3 Faculdade de Tecnologia Termomecanica (FTT). São Bernardo do Campo, SP, Brasil.

https://orcid.org/0000-0003-2380-7491 E-mail: valeria.feitosa.vv@usp.br
} 
and experienced in work environments. In this sense, we use as theoretical contributions the binomial communication and work and ergological studies. The data were collected through questionnaires and showed that the organizations confer parameters for freedom of expression. The right to freedom of expression is recognized and valued, but the limits are embedded in contexts in which workers have little scope to establish them. Concerns about damage to the company and the maintenance of good living together are the main reasons for the need of limits. Possible security risks and damage to the image of both workers and organizations spread as a consequence of a free expression.

Keywords: Freedom of expression; communication and work; human rights. 


\section{Introdução}

As pesquisas sobre liberdade de expressão são tributárias de uma longa tradição de reflexão realizada nos domínios da Filosofia e dos estudos jurídicos, que acabam por estabelecer os parâmetros para a fixação desse direito no ordenamento legal e para o julgamento dos conflitos advindos da colisão dos direitos fundamentais em sociedades definidas pelo modelo de democracia liberal (FARIAS, 2008; MELLO, 2015; GIRARD, 2016). Pesquisas desenvolvidas no domínio das Ciências da Comunicação (COSTA, 2013, 2019; FERIN, 2014; LIMA, 2015) tratam a liberdade de expressão como princípio a ser valorizado nas sociedades democráticas liberais, inserindo-se numa memória discursiva que remonta às conquistas da modernidade europeia. No caso brasileiro, dada a dificuldade de consolidação do ideário democrático, as pesquisas acerca da liberdade de expressão também são marcadas pela reflexão sobre a censura (CARNEIRO, 2002; COSTA, 2013; GOMES, 2010; KUSHNIR, 2004) e concentram-se na observação da esfera pública, sobretudo das práticas culturais como as artes e as comunicações. Contudo, outros domínios da vida social, a exemplo do mundo do trabalho e suas relações de comunicação, estão apagados dessa reflexão.

Esse cenário nos incentivou a elaborar um estudo empírico de caráter exploratório com objetivo de analisar como a liberdade de expressão é vivenciada e significada no mundo do trabalho, mais precisamente em ambientes organizacionais, marcados pelo controle das atividades, por regras, normas e processos. Em suma, buscamos compreender os sentidos e as práticas de liberdade de expressão na tensa relação entre indivíduos e organizações, que têm como pano de fundo a relação capital/trabalho, num contexto contraditório de desenvolvimento dos regimes produtivos em que predominam a racionalização e a competitividade (ANTUNES, 2011, 2018; HARVEY, 2008) ao mesmo tempo que se valorizam a autonomia, a flexibilidade e a liberdade (BOLTANSKI; CHIAPELLO, 2009; LINHART, 2007). Dessa forma, nos questionamos sobre os fatores que determinam a experiência da liberdade de expressão em contextos laborais, considerados como espaços de mediação cultural 
e que relações de comunicação podem ser estabelecidas. Neste artigo, discutimos, à luz do binômio comunicação e trabalho (FIGARO, 2009) e dos estudos ergológicos (SCHWARTZ, 2000), resultados obtidos, por meio de questionário respondido por 365 trabalhadores de sete organizações ${ }^{4}$ que compuseram a etapa quantitativa de nossa pesquisa, cujos aportes teóricos e a metodologia utilizada estão descritos adiante. Esta pesquisa foi concluída em 2018 e os resultados têm sido divulgados em eventos e artigos científicos (PACHI FILHO, 2017; 2018). Neste trabalho, destacamos aspectos relativos às definições de liberdade de expressão predominantes, à regulação da conduta e aos espaços de expressão.

\section{Comunicação e trabalho}

A reestruturação produtiva, que caracteriza o capitalismo desde as últimas décadas do século passado, tem imposto alterações significativas na inserção dos trabalhadores na estrutura de produção e modificado substancialmente a forma de ser, tanto do ponto de vista material quanto subjetivo dessa classe, conforme apontam Antunes (2009; 2011) e Linhart (2000; 2007). A criação de novos modelos produtivos, essenciais para a manutenção do capitalismo, deveria se aproximar dos desejos por maior flexibilidade e liberdade, entoados nas revoltas de trabalhadores e estudantes na Europa dos anos 1960, como nos informam Boltanski e Chiapelo (2009). Os aspectos da personalidade, as capacidades cognitivas e emocionais tornam-se o foco da atenção dos gestores num contexto em que a experiência e a qualificação perdem terreno (LINHART, 2007). Emerge um modelo que privilegia a individualização e acena com a possibilidade de uma realização das potencialidades subjetivas. Nesse novo cenário, busca-se colocar o trabalhador, como indivíduo, no centro do processo produtivo. Para Linhart (2007), porém,

4 Participaram desta pesquisa empresa do setor elétrico,empresa do setor de publicidade e propaganda, empresa do setor de recursos humanos, empresa do setor de transportes, empresa do setor de tecnologia da informação, organização de ensino e organização de educação, cultura e lazer. 
a individualização progride a passos largos e no mesmo ritmo das contradições que derivam das lógicas produtivas.

Com tais mudanças, que não se constituem em um novo modelo de organização da sociedade, o trabalhador continua subordinado ao sistema produtivo e ao universo empresarial. Como resultado da lógica do capital, tal como aborda Antunes (2011, p. 47), temos efeitos visíveis como a expansão do desemprego estrutural, redução do trabalho industrial e fabril, aumento do subproletariado e do trabalho precário.

Outra consequência desse processo foi a expansão da parte linguageira do trabalho, como explica Boutet (2016). A comunicação assume papel determinante para a nova gestão simbólica demandada nos contextos organizacionais. Desse modo, é necessário pensar as articulações entre linguagem, as práticas comunicacionais e os lugares de mediação dos discursos presentes na sociedade, entre eles o mundo do trabalho, onde também ocorre o reprocessamento dos valores (SCHWARTZ, 2000) que sedimentam a sociedade e alimentam o discurso social.

Lacoste (2001) explica que a comunicação no trabalho permanece oculta devido ao desenvolvimento da comunicação empresarial, que investe em técnicas, discursos, profissionalização e contribui para manter na sombra uma realidade mais antiga e essencial, que é ligada aos processos de trabalho. Essa autora afirma que as visões sobre o trabalho desenvolvidas nas organizações permanecem dominadas pela obsessão da tecnologia, da automação e pela racionalização organizacional. Nesse contexto, a ideia mesmo de comunicação é perturbadora e de difícil apreensão pelas práticas que regem o mundo corporativo.

Ao formular o binômio comunicação e trabalho, Figaro (2009) promove o deslocamento da comunicação do universo da gestão para o mundo do trabalho, gesto que permite pensá-la a partir de relações de sentido variadas e não padronizadas e/ou uniformizadas conforme se pretende na gestão dessa comunicação. $\mathrm{O}$ mundo do trabalho, conforme o define Figaro (2008a), é uma categoria ampla e atravessada por discursos, valores, ideologias variadas e grupos sociais distintos. 
A atividade de trabalho, explica Figaro (2009) com base em Schwartz (2000), permite ao sujeito criar algo em benefício de si e dos outros a partir de prescrições consolidadas e de sua experiência pessoal (conhecimento investido). O trabalho, na concepção proposta por Schwartz, é o espaço em que as normas se confrontam com a subjetividade do trabalhador. O que ocorre é um constante intercâmbio entre os saberes formalizados e os que se originam na prática dos trabalhadores $\mathrm{SCH}$ WARTZ; DURRIVE, 2010). Assim, os trabalhadores fazem uso de sua história, de seus valores e os utilizam para executar as atividades, reinventando constantemente as normas que lhe são prescritas. Por isso, Schwartz (2000) forja o conceito de corpo-si para abarcar as diferentes experiências e temporalidades presentes na atividade laboral. O corpo-si articula história pessoal, social e cultural. Na atividade do trabalho, é impossível não fazer escolhas conforme valores, o que abre caminho para uma discussão acerca das liberdades - entre elas a liberdade de expressão - que possibilitam as escolhas do corpo-si (SCHWARTZ; DURRIVE 2010, p. 71). Na perspectiva ergológica, deve-se compreender que o sujeito faz uso de si por si mesmo num jogo com o uso que os outros fazem do sujeito, processos denominados de "dramáticas do uso de si por si mesmo e por outros” (SCHWARTZ; DURRIVE, 2010).

Segundo Figaro (2008a), a comunicação no mundo do trabalho se dá pelas interações necessárias à atividade de trabalho e às necessidades de gestão de si por si mesmo e de si pelos outros. Ela é a categoria de análise reveladora de reações e interações que se dão entre subjetividades, condição constitutiva do ser humano. Assim, na perspectiva de Figaro, trabalho e comunicação são centrais na constituição das relações sociais, o que inclui os processos produtivos. A atividade de trabalho, que depende da ação do homem, é articulada pela atividade de comunicação, no trabalho social que caracteriza a própria espécie. Nesse sentido, o trabalho é tratado como espaço de mediação ${ }^{5}$.

5 A ideia de mediação corresponde a um modo de estar na realidade, que é social, psicológico e cultural, que permite ao ser humano interpretar o mundo por meio de sua inserção histórico-cultural (BRAGA, 2012, p. 32). 


\section{Metodologia}

A ausência de dados e estudos sobre as relações entre liberdade de expressão e as variáveis presentes no mundo do trabalho nos motivou a desenvolver um estudo empírico e exploratório no campo das Ciências da Comunicação para compreender a circulação de sentidos sobre a liberdade de expressão em contextos organizacionais, aqui compreendidos como parte do mundo do trabalho. Os estudos exploratórios têm como objetivo preparar o terreno para pesquisas posteriores ou para abordar temas ainda pouco estudados, permitindo que o pesquisador se familiarize com as questões que envolvem seu objeto de estudo (SAMPIERI; COLLADO; LUCIO, 2006). Na pesquisa como um todo, adotamos as propostas teórico-metodológicas de Figaro (2008a, 2008b, 2013). O desenho metodológico proposto por essa autora, adaptado à complexidade e interdisciplinaridade necessária nos objetos de estudo no campo da Comunicação, inclui etapas quantitativa e qualitativa. Neste artigo, apresentamos resultados parciais obtidos para a etapa quantitativa, que contou com coleta de dados por meio de questionário com trabalhadores de sete organizações.

O questionário, com 74 questões, utilizado para a coleta de dados dos trabalhadores foi dividido em nove blocos, a saber: dados pessoais, conhecimento sobre direitos humanos e liberdade de expressão, regulação da conduta e liberdade de expressão, espaços de expressão, acesso a meios de comunicação, monitoramento e controle de meios de comunicação, expressão em meios de comunicação, expressão política e sindical e expressão individual. Marchesan e Ramos (2012) explicam que os questionários são instrumentos desenvolvidos para coletar dados que não estão diretamente disponíveis e que não podem ser obtidos pela observação. Seu objetivo, como alerta Gil (1999, p. 128), é o de conhecer, por um número mais ou menos elevado de questões, opiniões, crenças, sentimentos, interesses e situações vivenciadas.

Procuramos na elaboração do questionário apreender o sentido contemporâneo de liberdade de expressão, como ele se fixa no discurso social, a partir dos documentos juridicamente consagrados, como a 
Constituição Federal Brasileira (1988), a Declaração Universal de Direitos Humanos (1948), e documentos de instituições multilaterais, a exemplo da Organização dos Estados Americanos (2015), da Organização Internacional do Trabalho (2013) e da Organização das Nações Unidas para Educação, Ciência e Cultura (2016). Buscamos também explorar os sentidos estabelecidos para a liberdade de expressão no âmbito da administração que a inclui, como demonstra França (2010), em questões relativas à qualidade de vida e à gestão participativa, e em documentos e organizações empresarias como o Instituto Ethos de Empresas e Responsabilidade Social (2011). Adotamos ainda as categorias propostas por Barry (2007) sobre liberdade de expressão no ambiente de trabalho, que englobam as liberdades de crença, fala, de divulgação e de associação.

Em pesquisas basicamente qualitativas, como a que realizamos, a amostra se define como unidade de análise ou grupo de pessoas, contextos, eventos, fatos, comunidades, sobre os quais deverão ser coletados dados sem a necessidade de representatividade do universo ou da população (SAMPIERI; COLLADO; LUCIO, p. 251-252). Nesta pesquisa, constituímos amostras não probabilísticas de empresas e trabalhadores. Assim, conforme explicam Sampieri, Collado e Lúcio (2006, p. 271), a escolha dos indivíduos para a composição das amostras não probabilísticas depende do pesquisador e sua vantagem para estudos qualitativos reside no fato de que elas são úteis para modelos de pesquisa que não requerem representatividade de elementos.

A formação da primeira amostra, constituída por organizações, foi determinada por julgamento, processo adequado para escolher elementos típicos e representativos e em pequeno número. Procurarmos selecionar organizações que se comprometem publicamente com o respeito aos direitos humanos. Optamos por este perfil por haver adesão a um discurso empresarial que enfoca a cidadania e por supostamente serem mais permeáveis a diversas significações sobre liberdade de expressão. Do total de 43 empresas contatadas, 7 concordaram em participar da pesquisa, mediante a confidencialidade de seus dados, nomes, produtos 
e identidade de seus trabalhadores. A segunda amostra foi composta por trabalhadores dessas empresas. Por não termos a pretensão de inferência estatística neste momento da pesquisa e dado o perfil exploratório do estudo, não estabelecemos critérios para a seleção dos respondentes. No total, 365 trabalhadores responderam ao questionário aplicado em cada uma das sete organizações participantes da pesquisa, nos anos de 2016 e 2017, números considerados suficientes para identificarmos padrões e tendências e para termos uma dimensão geral sobre temas abordados.

Os dados foram organizados em uma única base com a utilização de planilhas eletrônicas. Em seguida, as variáveis foram codificadas e os dados importados para o software Statistical Package for Social Science for Windows (SPSS versão 18$)^{6}$ com a finalidade de análise estatística descritiva, instrumento que permite elaboração de tabelas de frequência e o entendimento das regularidades e tendências que podem ser observadas em grandes quantidades de dados (COOPER; SCHINDLER, 2011).

\section{Direito de expressão}

A liberdade de expressão ${ }^{7}$ entendida como direito de se expressar sem constrangimentos, de acordo com padrões estabelecidos pela legislação e pelo respeito aos outros direitos, é a definição mais adequada para esse valor, de acordo com 62,5\% dos respondentes (Figura 1). Outros 24,1\% acreditam que a liberdade de expressão é o direito de se expressar sem constrangimentos respeitando limites estabelecidos pela legislação e por instituições, como empresas. Apenas 13,4\% acreditam que a liberdade de expressão é o direito de se expressar sem constrangimentos ou sem limites. Na atualidade, o debate sobre esses significados, sobre os comportamentos expressivos e a coexistência da liberdade de expressão com

6 O Statistical Package for Social Science for Windows (SPSS) é um software para análise estatística de dados, que permite realizar cálculos complexos e visualizar seus resultados de forma simples e autoexplicativa. Este programa faz análise descritiva inicial completa das respostas obtidas e também da consistência interna do questionário.

7 Neste tópico, as análies foram feitas com base nas respostas às seguintes proposições de múltipla escolha: "Liberdade de expressão pode ser definida como": e "Limites à liberdade de expressão devem ser definidos por:" 
outras liberdades fundamentais e outros interesses sociais têm sido alvo de preocupação de filósofos e juristas, como demonstra Ramond (2016) e também da própria sociedade, como atestamos em nossa pesquisa. A delimitação filosófica e jurídica, cujo denominador comum, segundo Girard (2016), pode ser definido como o direito de se expressar sem sofrer interferências arbitrárias é insuficiente para delimitar as formas de expressão e os critérios para estabelecer as arbitrariedades.

Em nossa pesquisa, pudemos observar que a lei é um parâmetro dominante para a definição de liberdade de expressão entre os trabalhadores, porém não se pode desconsiderar o papel de instituições, sobretudo no que concerne aos limites para este valor. Ao considerarmos quem deve estabelecer limites para a liberdade de expressão, observamos que não apenas a legislação, mas as instituições têm papel admitido como relevante (Figura 2). Instituições como empresas e organizações da sociedade e a legislação são consideradas como instâncias encarregadas de limitar a liberdade de expressão por 36,2\% dos respondentes. Outros $30,1 \%$ acreditam que é função apenas dos representantes da população estabelecerem, por meio das leis, os limites para a liberdade de expressão. Parcela significativa $(25,8 \%)$ acredita que não devem existir limites à expressão. Os 7,9\% restantes acreditam que cabe apenas às instituições da sociedade estabelecerem tais limites. Podemos observar que as instituições concorrem com a lei na tarefa de limitação da liberdade de expressão, não havendo consenso de que a fonte exclusiva para que esses limites sejam estabelecidos é pela ação política e legal. Há uma tendência da parte dos trabalhadores à aceitação de normas limitadoras de origem institucional, que não pode ser menosprezada e um afastamento do campo da política e dos direitos como definidores primários dos limites para a expressão. Neste aspecto, sentidos e limites para a liberdade de expressão também podem ser localizados e variáveis conforme as práticas institucionais, sejam elas determinadas em instâncias superiores ou abertas à participação dos trabalhadores. 
Figura 1 - Definição de liberdade de expressão

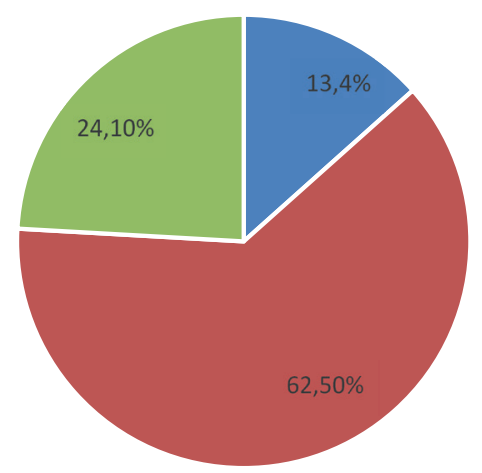

- O direito de se expressar sem constrangimento e sem limites

- O direito de se expressar sem constrangimento respeitando limites definidos pelo respeito aos outros direitos e pela legislação

- O direito de se expressar sem constrangimentos de acordo com limites definidos pela legislação e por instituições como empresas e outras organizações da sociedade

Fonte: Elaboração dos autores

Figura 2 - Definição de limites para a expressão

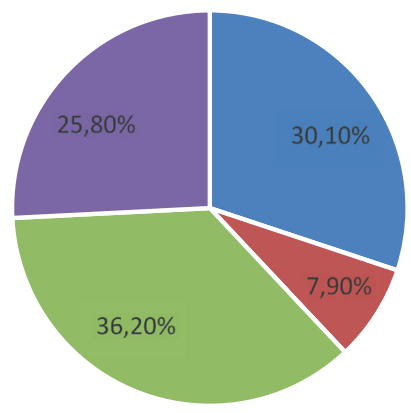

- Exclusivamente pela legislação aprovada pelos representantes da população

- Pelas instituições como empresas e demais organizações da sociedade

- Pelas instituições como empresas e demais organizações da sociedade e pela legislação

- Não deve haver limites à expressão

Fonte: Elaboração dos autores 


\section{Regulação da expressão}

Os limites para a expressão nas organizações ${ }^{8}$ (Figura 3), para as quais os participantes da pesquisa trabalham, são, em sua maioria, definidos de modo informal, como atestam 35,6\% dos respondentes. Outros 26,8\% reconhecem esses limites definidos em documentos da empresa. Correspondem a 18,2\% os que afirmam não haver limites para a expressão, e 19,4\%, além de afirmarem não existirem limites, se sentem livres para expressar opiniões, críticas e sentimentos. Em suma, a maioria reconhece a existência de limites. Dos que reconhecem a existência dos limites (62,4\% da amostra), $50,4 \%$, porém, disseram não saber a forma como eles são estabelecidos e outros 49,6\% disseram ter conhecimento como os limites se estabelecem. Podemos perceber que a vigência da informalidade não impede que os limites sejam reconhecidos e integrem as rotinas de trabalho. Parcela expressiva dos respondentes desconhece como são constituídos tais limites, o que nos leva a pensar que as regras tendem a ser formuladas externamente aos coletivos de trabalho.

Os que afirmaram conhecer os limites para a expressão disseram em sua maioria $(55,2 \%)$ que os limites são estabelecidos em códigos e comitês de ética na organização. Outros $21 \%$ disseram que os limites são diretamente delimitados por chefes e 16,4\% afirmaram que a empresa define limites para a expressão por comunicados. Apenas 7,4\% afirmaram que os limites são estabelecidos em discussões abertas e com a participação de funcionários (Figura 4). Podemos observar, portanto, que entre os trabalhadores que reconhecem os limites não há a percepção de participação no seu estabelecimento, sendo que fica a cargo das organizações defini-los, ainda que se valham de mecanismos como códigos de ética e comitês. A definição de limites por meio de superiores hierárquicos ou por comunicados, cuja origem são as instâncias de direção, também é significativa e demonstra que o limite da expressão, quando reconhecido pelos trabalhadores, ocorre em esferas de poder

8 Análises elaboradas com base nas respostas às questões: Na empresa onde você trabalha, há limites para expressão?; Você tem conhecimento como são estabelecidos limites à expressão?; Os limites prejudicam a livre expressão?; Os limites para a expressão prejudicam o trabalho? Os limites para a expressão são necessários? 
não acessíveis a sua participação. Logo, a expressão dos trabalhadores parece sujeita e condicionada às normas de ordem institucional, que afetam a comunicação e a circulação de sentidos sobre a própria liberdade de expressão.

Figura 3 - Limites para a expressão na organização

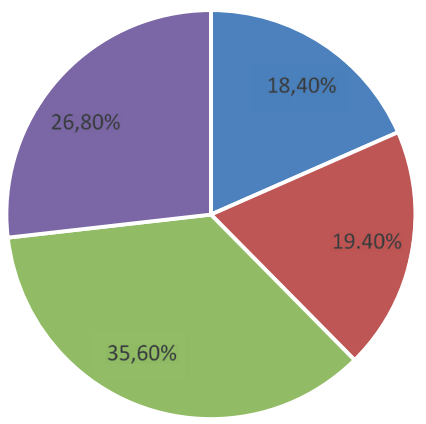

- Não há limites definidos para a expressão dos trabalhadores

- Não há limites para a expressão dos trabalhadores e me sinto livre para expressar opiniões, sentimentos e críticas

- Sim, eles existem, mas não estão definidos em documentos da empresa

- Sim, eles são definidos em documentos da empresa

Fonte: Elaboração dos autores

Figura 4 - Como são estabelecidos os limites

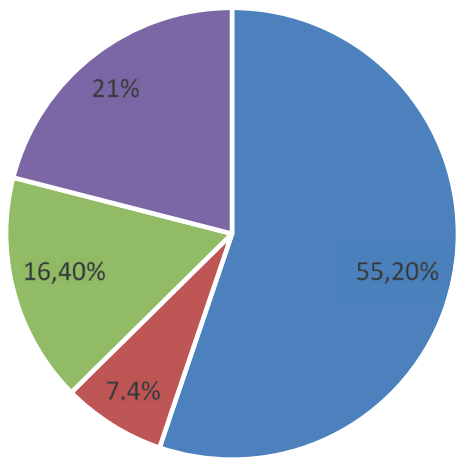

- Os limites são definidos em comitês de ética e no código de ética da organização

- Os limites são definidos em discussões abertas e com a participação dos funcionários

- Os limites são definidos pela empresa por meio de comunicados

- Os limites são definidos pelos chefes

Fonte: Elaboração dos autores 
Ainda assim, 62,4\% consideram que os limites não prejudicam a expressão dos trabalhadores e 37,6\% afirmaram que há prejuízo. Quanto à atividade de trabalho, $78 \%$ consideram que os limites estabelecidos não a prejudicam e outros $22 \%$ veem neles prejuízos para a realização do trabalho. Duas hipóteses podem ser formuladas a partir desses dados: os limites não geram incômodos reais ou foram admitidos como parte do processo de trabalho por quem o realiza. Some-se a isso o fato de que $75,9 \%$ consideram os limites à liberdade de expressão necessários e 24,1\% acreditam que estes limites não o são. Há assim grande concordância dos trabalhadores aos limites estabelecidos, que se tornam, portanto, parte da sua vivência no ambiente de trabalho. Cristaliza-se a ideia de que os limites estabelecidos pela organização são necessários para que o trabalho seja realizado.

Em questão com mais de uma resposta possível ${ }^{9}$, buscou-se investigar as razões pelas quais os limites são considerados necessários por aqueles que concordam com sua existência (Figura 5). Evitar danos de imagem à organização e a manutenção da boa convivência foram alternativas que receberam maior número de respostas, seguidas por itens como manutenção de informações sigilosas e segurança dos trabalhadores. A livre expressão, na visão dos respondentes que consideram os limites necessários, configura-se como ameaça primeiramente para empresa, que pode sofrer danos de imagem e comprometer sua segurança. Num segundo plano, os trabalhadores também podem ter ameaçadas sua segurança e sua imagem. A convivência também pode ser prejudicada e os limites institucionalmente adotados serviriam para preservar as relações no trabalho. Desse modo, percebe-se a centralidade da organização no que se refere à necessidade de limitação da expressão, que se torna um risco a ser considerado, fato que tem concordância significativa entre os respondentes da pesquisa.

9 Consideramos aqui o total de respostas obtidas para cada item na resposta à questão "Por que você considera estes limites necessários?” no conjunto das empresas e organizações pesquisadas. O mesmo procedimento foi adotado para os dados apresentados nas Figuras 6,7 e 8 
Figura 5 - Por que razão os limites são necessários

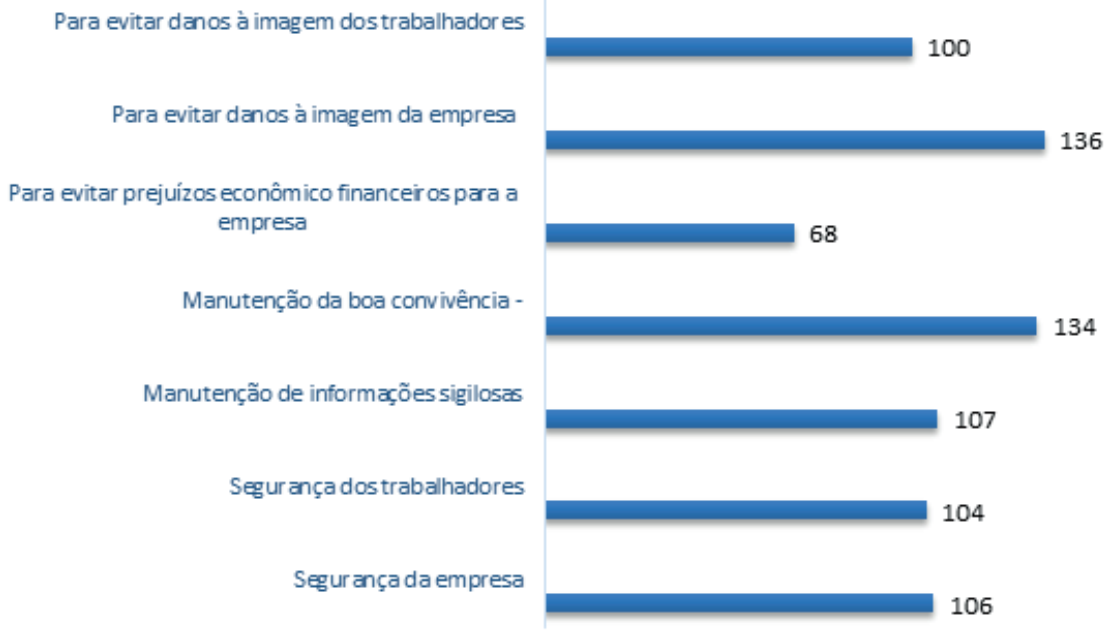

Fonte: Elaboração dos autores

\section{Espaços de expressão}

Parcela pouco expressiva $(21,4 \%)$ dos respondentes diz participar de comitês de gestão existentes nas organizações pesquisadas ${ }^{10}$. A grande maioria $78,6 \%$ se mantém à margem da participação nesses comitês. Reuniões periódicas, ouvidoria e comissões internas são os canais mais citados para expressão dos trabalhadores (Figura 6). Nesse cenário, 67,15\% consideram os canais disponíveis para a manifestação dos trabalhadores, como ouvidoria, canais de denúncia, reuniões e comissões internas, suficientes para garantir a liberdade de expressão. Outros $32,85 \%$, por sua vez, consideram tais canais insuficientes. Em sua maioria (80,8\%), os trabalhadores se sentem estimulados a dar sugestões para melhorar as práticas e as condições de trabalho, o que não ocorre na visão de 19,2\% dos participantes da pesquisa. O estímulo à expressão com vistas à contribuição para a melhora

10 Análises feitas com base nas respostas para as questões: "Você participa de comitês de gestão na empresa?; A empresa mantém que canais de expressão?; Os canais disponíveis são suficientes para garantir a liberdade de expressão? Você se sente estimulado e livre para dar sugestões para melhorar as práticas e condições de trabalho? 
dos processos de trabalho é uma das características de gestões modernas inspiradas no modelo toyotista, em que a expressão do trabalhador é incentivada de modo que ele se envolva com o projeto empresarial e se responsabilize pelo cumprimento das metas estabelecidas. Tais espaços são pensados para capturar a expressão dos trabalhadores em benefício da organização e para diminuir o risco derivado de conflitos inerentes à relação capital/trabalho (ANTUNES, 2011; LINHART, 2007).

Figura 6 - Canais para expressão

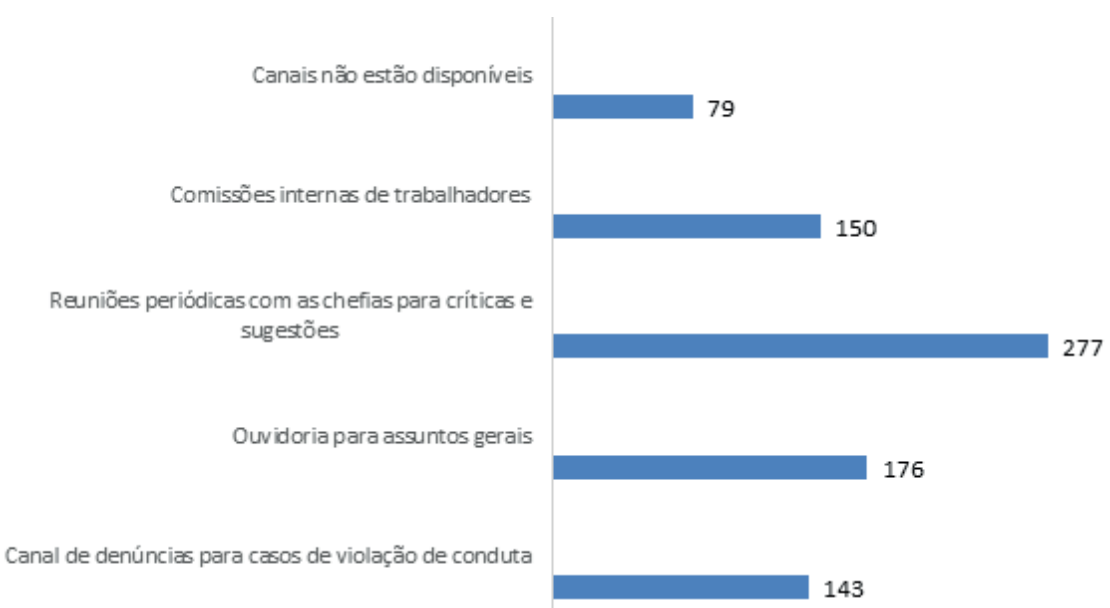

Fonte: Elaboração dos autores

As situações consideradas mais livres (Figura 7) ${ }^{11}$ para a expressão são as que se referem à convivência com colegas de trabalho, seguida pela sensação de liberdade nas atividades de trabalho, se analisadas de modo geral, e pela convivência com superiores hierárquicos. O contato com clientes e fornecedores, públicos externos à organização, foi o item que recebeu o menor número de respostas. A convivência com colegas de trabalho, em que os laços informais são mais estabelecidos, garante maior liberdade de expressão. A convivência com os superiores não parece impor limites à expressão. Sabemos que a gestão moderna visa

11 Análise realizada com base na resposta à questão "Em que situações você considera que sua expressão é livre na empresa onde você trabalha? (mais de uma resposta pode ser assinalada)" 
à proximidade entre líderes e liderados na busca de estabelecer uma relação de confiança, na qual os conflitos sejam resolvidos com base no diálogo (LINHART, 2007). É necessário compreender que os coletivos de trabalho têm contornos variáreis, como aponta Schwartz (2010b, p. 151). Para tanto, este autor formula o conceito de entidades coletivas relativamente pertinentes (ECRP). Se os ambientes de trabalho são espaços onde a vida se processa, os coletivos se constituem dinamicamente e estão em permanente transição. Suas fronteiras são definidas pela atividade de trabalho em determinados momentos, de acordo com os laços estabelecidos pelos trabalhadores. É nos coletivos que ocorrem os debates de valores sociais e políticos, que são reprocessados no âmbito da atividade de trabalho. Desse modo, o que ocorre no âmbito da sociedade, no que se refere à gestão global das atividades econômicas e políticas, produz efeitos nas atividades e nos meios de trabalho, onde ocorre o reprocessamento do debate social. Como consequência, há um entrelaçamento entre os valores discutidos no campo social e aqueles reprocessados no trabalho, de modo que um interfere no outro.

Figura 7 - Situações em que a expressão é livre

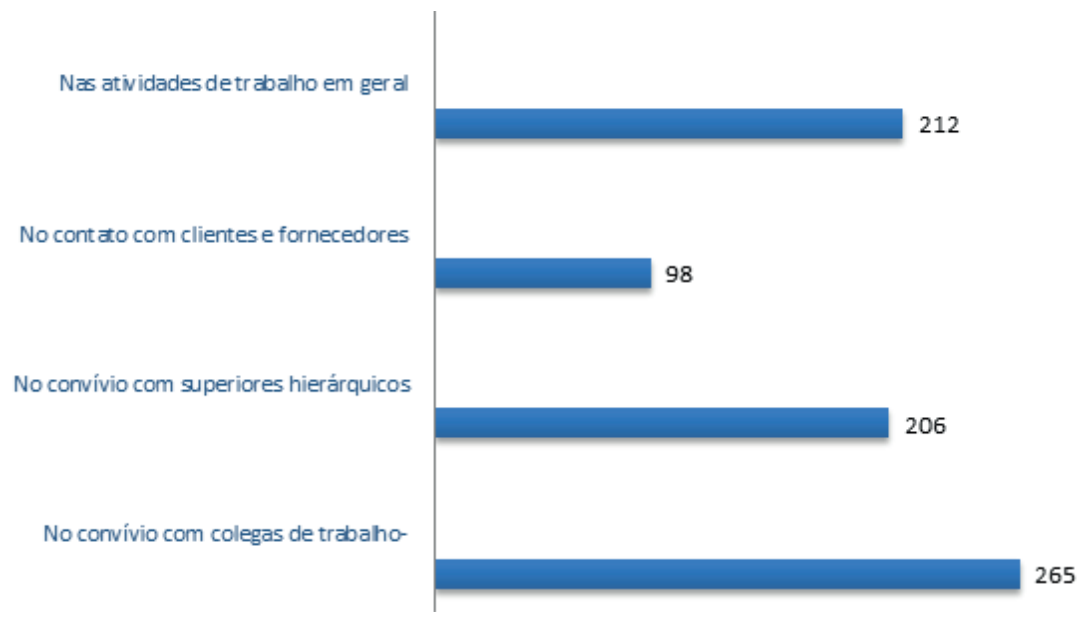

Fonte: Elaboração dos autores 
De modo geral, buscou-se investigar fatores que impedem a livre expressão na organização onde os participantes da pesquisa trabalham ${ }^{12}$ (Figura 8). Em resposta à pergunta em que podiam ser assinaladas várias alternativas, o temor de se expor e não ser compreendido é a alternativa mais marcada, seguida pelo temor de ofender outras pessoas, de sofrer represálias e de perder o emprego. Falta de habilidade para se comunicar e hostilidade nos ambientes foram fatores menos mencionados. $\mathrm{O}$ traço que se sobressai é o temor que os trabalhadores parecem ter de se expressar, ainda que as organizações abram espaço para a expressão. Notemos que a hostilidade à expressão presente no ambiente não foi um fator dos mais relevantes, mas não se pode desconsiderar que o temor de represálias por parte de superiores hierárquicos e da perda do emprego são aspectos mencionados, o que demonstra que há questões da ordem do funcionamento das organizações que podem limitar a expressão.

Figura 8 - O que impede a livre expressão

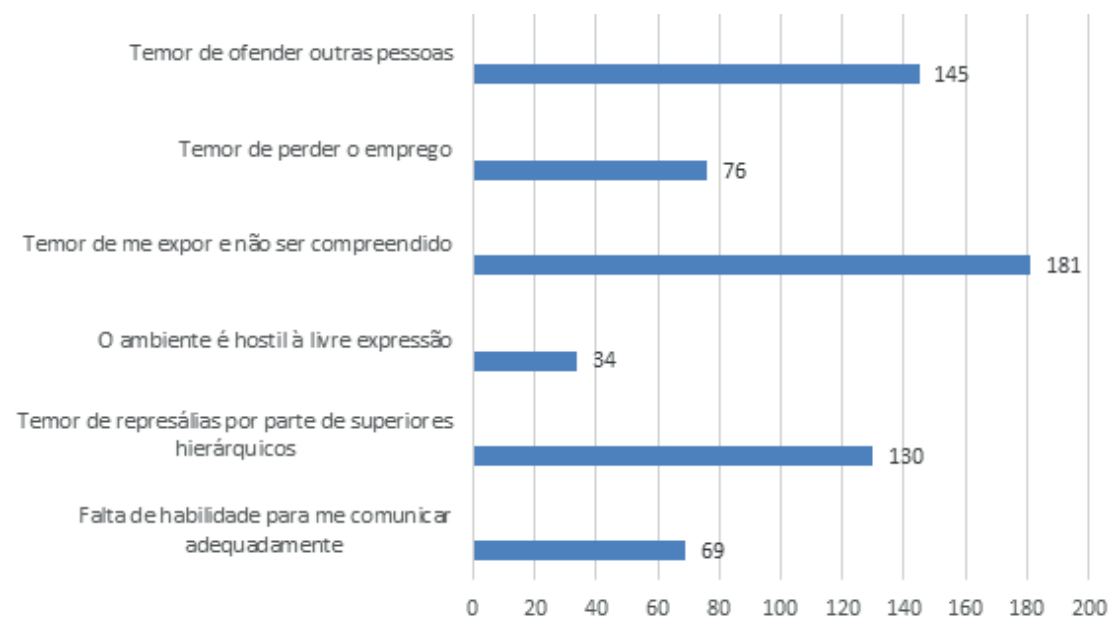

Fonte: Elaboração dos autores

12 Análise feita com base nas respostas à questão "Na sua visão, o que impede a sua livre expressão na empresa onde você trabalha? (mais de uma resposta pode ser assinalada)" 


\section{Considerações finais}

No que se refere aos trabalhadores, as respostas obtidas apontam para uma vivência que tende a ser determinada no ambiente de trabalho e pela organização. Para a maioria dos entrevistados, a liberdade de expressão é o direito de se expressar sem constrangimentos, de acordo com padrões estabelecidos pela legislação e pelo respeito aos outros direitos. Percebe-se assim que a liberdade de expressão é assegurada pela lei e seus limites devem ser considerados apenas em relação à lei e a outros direitos. No entanto, se a pergunta for direcionada para investigar quem deve estabelecer limites para a liberdade de expressão, podemos observar que há uma tendência significativa de admitir que outras instituições também o façam. Nesse aspecto, a aceitação de limites, não originados na esfera propriamente política e legal, encontra respaldo na visão de trabalhadores, considerando também que a minoria acredita que não deve haver limites à expressão. As prescrições relativas à liberdade de expressão têm, consequentemente, relevância para as relações de comunicação no trabalho na medida em que as regras e os limites estão postos nas organizações e não apenas na lei, afetando a gestão que os trabalhadores fazem de si próprios.

Ainda que as organizações procurem estabelecer formalmente os limites para a expressão e utilizem instrumentos como códigos de conduta e comitês de ética, boa parte dos respondentes afirma que os limites se estabelecem informalmente. O reconhecimento da existência de documentos que fixam limites para a expressão não é, portanto, generalizado. Também é possível dizer que metade do total de respondentes que reconhecem a existência de limites para expressão não sabe como os limites são estabelecidos, o que pode indicar que a participação dos trabalhadores no debate e na reflexão sobre a liberdade de expressão não é prática de fato existente, suficientemente difundida e/ou conhecida. Desse modo, o parâmetro para a liberdade de expressão é dado pela organização, ou seja, os trabalhadores sabem as restrições a que estão submetidos.

A maioria dos trabalhadores que identificam a existência formal de limites para a expressão afirma que eles são definidos em códigos e 
comitês de ética. Superiores hierárquicos e comunicados são também reconhecidos como fontes para a fixação dos limites da expressão. Poucos trabalhadores dizem haver discussões com os coletivos de trabalho para discussão sobre limites da expressão, o que corrobora nossa hipótese de que as instituições definem os limites nas instâncias hierárquicas e buscam impô-los aos trabalhadores como norma de conduta a ser seguida. Nesse cenário, a grande maioria parece não se incomodar com os limites e afirma que eles não prejudicam a realização das atividades de trabalho. Ademais, a maioria também os reconhece como necessários, prova de que há uma aceitação e normalização desses limites na prática. As preocupações com eventuais danos à empresa e a manutenção da boa convivência são as principais razões apontadas para a necessidade dos limites. Riscos à segurança e danos à imagem, tanto de trabalhadores quanto das organizações, se difundem como possíveis consequências negativas de uma expressão livre.

Os espaços de expressão abertos na organização para a manifestação dos trabalhadores são avaliados como suficientes pela maioria dos respondentes, que se consideram também estimulados para dar sugestões e contribuir para a melhoria do trabalho, fato que demonstra o funcionamento eficiente do aparato de captura da expressão montado nas organizações. No entanto, poucos deles participam de comitês de gestão. As situações mais livres para a expressão são aquelas vividas com colegas de trabalho ou com superiores hierárquicos, dados que sinalizam para as situações de convivência, informalidade e proximidade. As relações humanas estabelecidas no coletivo de trabalho parecem ter grande peso na percepção da liberdade de expressão. Mesmo assim, permanece um temor em relação à expressão, prova de que há uma associação entre expressão, medo e represálias. Se parte desses temores pode ser interpretada no nível psicológico, não há como negar que o medo de represálias aponta para um sistema no qual a valorização da expressão convive paralelamente com a adoção formal ou informal de punições que podem incidir sobre a própria expressão, limitando a comunicação. 


\section{Referências}

ANTUNES, R. Os sentidos do trabalho: ensaio sobre a afirmação e a negação do trabalho. São Paulo: Boitempo, 2009.

.Adeus ao trabalho?: ensaios sobre as metamorfoses e a centralidade no mundo do trabalho. 15. e. São Paulo: Cortez, 2011.

O privilégio da servidão. São Paulo: Boitempo, 2018.

BARRY, B. Speechless: the erosion of free expression in the american workplace. San Francisco: Berrett-Koehler Publishers, Inc., 2007.

BOLTANSKI, L.; CHIAPELLO, E. O novo espírito do capitalismo. São Paulo: Martins Fontes, 2009.

BOUTET, J. Atividades de linguagem em situações de trabalho. Parágrafo, [S.l.], v. 4, n. 1, 2016, p. 90-97. Disponível em: http://revistaseletronicas.fiamfaam.br/index.php/ recicofi/article/view/381. Acesso em: 4 jul. 2019.

BRAGA, J. L. Circuitos versus campos sociais. In: MATTOS, M.A.; JANOTTI JÚNIOR, J.; JACKS, N. (Orgs.). Mediação e midiatização: livro Compós, 2012. Salvador: Edufba, 2012, p. 31-52.

BRASIL. Constituição Federal de 1988. Promulgada em 5 de outubro de 1988. Disponível em: http://www.planalto.gov.br/ccivil_03/constituicao/constituição.htm. Acesso em: 30 abr. 2019.

CARNEIRO, M.L.T. Minorias silenciadas: história da censura no Brasil. São Paulo: Edusp, Imprensa Oficial/Fapesp, 2002.

COOPER, D. R.; SCHINDLER, P. S. Métodos de pesquisa em administração. 10. ed. Porto Alegre: Bookman, 2011.

COSTA, M. C. Opinião pública, comunicação, liberdade de expressão e censura. In: COSTA, M. C. (Org.). Comunicação, Mídias e Liberdade de Expressão. São Paulo: Intercom, 2013, p. 19-36.

COSTA, C. Liberdade de expressão e campanhas eleitorais. In: COSTA, C.; BLANCO, P. (Orgs.). Liberdade de expressão e campanhas eleitorais Brasil 2018. São Paulo: Palavra Aberta, 2019, p. 11-37.

DECLARAÇÃO UNIVERSAL DOS DIREITOS HUMANOS. Assembleia Geral das Nações Unidas em Paris. 10 dez. 1948. Disponível em: https:/nacoesunidas.org/direitoshumanos/declaracao/. Acesso em: 29 abr. 2019.

FARIAS, E. P. F. Colisão de direitos: a honra, a intimidade, a vida privada e a imagem versus a liberdade de expressão e informação. 3. ed. Porto Alegre: Sérgio Antonio Fabris Editor, 2008.

FERIN, I. Percurso das democracias: da liberdade de expressão. In: COSTA, M. C. C. (org.). Diálogos sobre censura e liberdade de expressão: Brasil e Portugal. São Paulo: ECA/USP, 2014, p. 7-13.

FIGARO, R. O mundo do trabalho e as organizações: abordagens discursivas de diferentes significados. Organicom, São Paulo, v. 5, n. 9, 2008a, p. 91-100. Disponível em: http://www.revistas.usp.br/organicom/article/view/138986. Acesso em: 4 jul. 2019.

FIGARO, R. Relações de comunicação no mundo do trabalho. São Paulo: Annablume, 2008b. 
FIGARO, R. Comunicação e Trabalho: binômio teórico produtivo para as pesquisas de recepção. Mediaciones sociales: Revista de Ciencias Sociales y de la Comunicación, n. 4, primer semestre de 2009, p. 23-49. Universidad Complutense de Madrid. Disponível em: https:/revistas.ucm.es/index.php/MESO/article/view/MESO0909120023A. Acesso em: 4 jul. 2019.

FIGARO, R. (Org.). As mudanças no mundo do trabalho do jornalista. São Paulo: Atlas, 2013.

FRANÇA, A. C. L. Qualidade de vida no trabalho - QVT: conceitos e prática nas empresas da sociedade pós-industrial. São Paulo: Atlas, 2010.

GIL, A. C. Métodos e técnicas de pesquisa social. 5. ed. São Paulo: Atlas, 1999.

GIRARD, C. La liberté d'expression : état des questions. Raisons politiques, 2016/3, n. 63, p. 13-33. Disponível em: https:/www.cairn.info/revue-raisons-politiques-2016-3-page-13.htm. Acesso em: 30 abr. 2019.

GOMES, M.R et. al. Palavras proibidas. São Paulo: Fapesp/Bluecom, 2010.

ILO. Decent work indicators : guidelines for producers and users of statistical and legal framework indicators. Genebra: ILO, 2013. Disponível em: http://www.ilo.org/stat/Publications/WCMS_223121/lang--en/index.htm. Acesso em: 20 jun. 2016.

KUSHNIR, B. Cães de guarda: jornalistas e censores, do AI-5 à Constituição de 1988. São Paulo: Boitempo, 2004.

HARVEY, David. Condição pós-moderna: uma pesquisa sobre as origens da mudança cultural. 17. ed. São Paulo: Loyola, 2008.

INSTITUTO ETHOS. Empresas e direitos humanos na perspectiva do trabalho decente: marco de referência. São Paulo: Instituto Ethos, 2011.

LACOSTE, M. Peut-on travailler sans communiquer? In: BORZEIX, A. ; FRAENKEL, B. Langage et travail: communication, cognition, action. Paris: CNRS, 2001, p. 1-28.

LIMA, V. Cultura do silêncio e democracia no Brasil: ensaios em defesa da liberdade de expressão. Brasília: Editora UNB, 2015.

LINHART, D. O indivíduo no centro da modernização das empresas: um reconhecimento esperado, mas perigoso. Trabalho ๒ Educação, Belo Horizonte, n. 7, jul.-dez. 2000, p. 24-36. Disponível em: https://seer.ufmg.br/index.php/trabedu/article/download/7591/5878. Acesso em: 20 dez. 2017.

LINHART, D. A desmedida do capital. São Paulo: Boitempo, 2007.

MARCHESAN, M. T. N.; RAMOS, A. G. Check list para a elaboração e análise de questionários em pesquisas e crenças. Domínios da lingu@gem, Uberlândia, v. 6, n. 1, 2012. Disponível em: http://www.seer.ufu.br/index.php/dominiosdelinguagem/article/ view/14796/9613. Acesso em: 1 jul. 2017.

MELLO, C. M. F. Direito de crítica do empregado nas redes sociais: e a repercussão no contrato de trabalho. São Paulo: LTR, 2015.

OEA. Relatoria especial para liberdade de expressão. Disponível em: http://www.oas. org/pt/cidh/expressao/. Acesso em: 25 fev. 2015.

PACHI FILHO, F. F. Autocontrole da expressão e privacidade no mundo do trabalho. In: COSTA, M. C. C. (Org.). Privacidade, sigilo e compartilhamento. São Paulo: ECA-USP, 2017, p. 77-84 Disponível em: http://www.livrosabertos.sibi.usp.br/portaldelivrosUSP/ catalog/view/154/133/662-2. Acesso em: 10 mar. 2020. 
PACHI FILHO, F. F. Sentidos da liberdade de expressão no mundo do trabalho. In: $41^{\circ}$ Congresso Brasileiro de Ciências da Comunicação - Intercom, 2018, Joinville, SC. Anais (online). São Paulo: Intercom, 2018. Disponível em: Acesso em: <http://portalintercom.org.br/anais/nacional2018/resumos/R13-2096-2.pdf> Acesso em: 10 mar. 2020. RAMOND, D. Liberté d'expression. Le temps d'en parler. Raisons politiques, v. 63, n. 3, 2016, p. 5-11. Disponível em: https://www.cairn.info/revue-raisons-politiques-2016-3-page-5.htm. Acesso em: 4 jul. 2019.

SAMPIERI, R. H.; COLLADO, C. F.; LUCIO, P. B. Metodologia de pesquisa. São Paulo: McGraw-Hill, 2006.

SCHWARTZ, Y. Le paradigme ergologique ou un métier de philosophe. Toulouse: Octarès, 2000.

SCHWARTZ, Y. A dimensão coletiva do trabalho e as Entidades Coletivas Relativamente Pertinentes (ECRP). In: SCHWARTZ, Y.; DURRIVE, L. (Org.). Trabalho \& Ergologia: conversas sobre a atividade humana. 2. ed. Niterói: EdUFF, 2010b, p. 147-164.

SCHWARTZ, Y.; DURRIVE, L. (Org.). Trabalho e ergologia: conversas sobre a atividade humana. 2. ed. Niterói: EdUFF, 2010.

UNESCO. Tendências mundiais sobre liberdade de expressão e desenvolvimento da mídia. Brasília: Unesco, 2016.

\section{Sobre os autores}

Fernando Felício Pachi Filho - Professor de Comunicação na Universidade Paulista e na Faculdade de Tecnologia Termomecânica. Doutor em Linguística pela Universidade Estadual de Campinas. No presente artigo, o autor participou do desenho da pesquisa, do desenvolvimento da discussão teórica, da coleta e interpretação dos dados, da redação do manuscrito e da revisão do texto.

Valéria Feitosa de Moura - Professora de Administração na Faculdade de Tecnologia Termomecânica. Doutoranda em Administração pela Faculdade de Economia, Administração e Contabilidade da Universidade de São Paulo (FEA-USP). No presente artigo, a autora participou do desenho da pesquisa, da interpretação dos dados e da revisão do texto.

Data de submissão: 04/07/2019

Data de aceite: 06/03/2020 